\title{
DEFORMACIONES ARTIFICIALES DEL CRÁNEO EN CAZADORES-RECOLECTORES DEL HOLOCENO MEDIO-TARDÍO DEL NOROESTE DE PATAGONIA
}

\author{
S. IVAN PEREZ;, CLAUDIA DELLA NEGRA*", PAULA NOVELLINO"**, \\ PAULA N. GONZALEZ", VALERIA BERNAL", ESTELA CUNEO", ADAM HAJDUK"*”*
}

\begin{abstract}
RESUMEN
El objetivo de este trabajo es analizar la variación en las deformaciones artificiales del cráneo observada en el noroeste de Patagonia e incorporarla a la discusión acerca de los patrones de variación temporal y espacial a escala supra-regional. Se analizó una muestra de 28 cráneos de individuos adultos procedentes de sitios arqueológicos de la provincia de Neuquén. Con fines comparativos se incluyeron 12 muestras procedentes de la región pampeana y del noreste y centro de Patagonia. La variación en las deformaciones artificiales fue descripta mediante el empleo de coordenadas de landmarks y semilandmarks en 2 dimensiones en el contexto de técnicas derivadas de la morfometría geométrica. Los resultados obtenidos señalan la existencia de un marcado patrón temporal en la variación de las deformaciones artificiales del cráneo en Neuquén. Los sitios datados en ca 4.000 años AP se caracterizan por la presencia de deformaciones que exhiben compresión en la región del hueso occipital y en el frontal. Esta morfología se encuentra en los entierros del litoral atlántico del norte de Patagonia y en el sudeste de la región pampeana con cronologías posteriores a 3.300 años AP. En los sitios correspondientes al Holoceno tardío final se encuentran morfologías caracterizadas por la expansión del hueso frontal y la compresión en la zona del lambda. El mismo tipo de deformación se encuentra contemporáneamente desde el sur de Pampa hasta el río Chubut. En síntesis, nuestros resultados permiten extender la profundidad temporal de las deformaciones artificiales en el norte de Patagonia hasta el límite Holoceno medio-tardío y destacan el carácter supraregional de la distribución geográfica de las deformaciones.
\end{abstract}

PALABRAS CLAVE: Bioarqueología, deformación craneana, Neuquén.

* División Antropología, Facultad de Ciencias Naturales y Museo. Paseo del Bosque s/n, La Plata. Argentina CONICET. iperez@ fcnym.unlp.edu.ar; pgonzalez@fcnym.unlp.edu.ar; bernalv@fcnym.unlp.edu.ar.

* Dirección General de Patrimonio, Subsecretaría de Cultura, Gobierno de la Provincia del Neuquén. Neuquén. Argentina. dellanegra@neuquen.gov.ar, claudellanegra@hotmail.com, ecuneo@gmail.com

*** Museo Juan Cornelio Moyano, Mendoza, Argentina. CONICET pnovel@hotmail.com

Museo de la Patagonia F. P. Moreno, Administración de Parques Nacionales, Bariloche, Argentina. CONICET adamhajduk@ bariloche.com.ar 


\title{
ARTIFICIAL CRANIAL DEFORMATION IN HUNTER-GATHERERS OF LATE-MIDDLE HOLOCENE FROM NORTHWEST PATAGONIA
}

\begin{abstract}
The aim of this paper is to analyze the variation in artificial cranial deformation of northwestern Patagonia and to incorporate it into the discussion about the patterns of temporal and spatial variation on a supra-regional scale. We analyzed a sample of 28 adult skulls from archaeological sites from the province of Neuquén. For comparative purposes we also included 12 samples from Pampean Region and northeast and center of Patagonia. The variation in artificial deformation was described using coordinates of landmarks and semilandmarks in 2 dimensions within the context of geometric morphometric techniques. The results indicate the existence of a marked temporal variation in artificial cranial deformations in Neuquén. Sites dated ca 4000 years BP are characterized by compression in the occipital region and frontal bones. This morphology is also found in burials from northern Atlantic coast of Patagonia and South East Pampean Region with chronologies post 3300 years BP. The individuals dated within the final late Holocene show morphologies are characterized by the expansion of the frontal bone and that compression in lambda. The same type of deformation is contemporaneously found in Chubut River and South Pampa. In summary, our results allow to extend the temporal depth of the artificial deformation in northern Patagonia to the limit of late-middle Holocene, highlighting the supra-regional geographic distribution of cranial deformations.
\end{abstract}

KEY WORDS: Bioarchaeology, cranial deformation, Neuquén.

El registro bioarqueológico del sur de Sudamérica se caracteriza por la presencia de sitios con una frecuencia alta de individuos con deformación artificial del cráneo (Berón y Baffi 2003; Bórmida 1953-54; Cocilovo 1973; Dembo e Imbelloni 1938; Imbelloni 1923, 1924-25; Perez 2006). Esta práctica consiste en la alteración del crecimiento normal del cráneo durante los primeros años de vida mediante la aplicación de fuerzas externas tanto de forma intencional, con el fin de producir una forma específica, como no intencional, derivada de otro comportamiento (Buikstra y Ubelaker 1994; Dembo y Imbelloni 1938). Si bien la deformación resulta de prácticas culturales, en el primer caso ha sido vinculada principalmente a expresiones de identidad grupal, mientras que en el segundo caso sería resultado, por ejemplo, del empleo de bandas en la cabeza del niño para sostenerlo en la cuna (Blom 2005; Getszten 1993; Munizaga 1992; Torres-Rouff 2002, 2003; Brothwell 1981). A pesar de las diferencias en el grado de intencionalidad, tales actividades resultan en una modificación de la forma craneana que se encuentra asociada con las prácticas culturales desarrolladas durante la infancia (Buikstra y Ubelaker 1994; Brothwell 1981;
Torres-Rouff 2003), y en consecuencia expresan significado social (Torres-Rouff 2003).

Los estudios tendientes a la evaluación de esta práctica en el noreste de Patagonia han revelado un marcado patrón de variación temporal caracterizado por la ocurrencia de deformación planolámbdica entre los 400 y 1.500 años AP, deformación tabular oblicua alrededor de los 2.000 años AP, y deformación anular -también designada como variedad pseudo-circular del tipo tabular erecto por algunos autores- alrededor de los 3.000 años AP (Bernal et al. 2008; Gómez Otero y Dahinten 1997-1998; Perez 2006). Este mismo patrón de distribución temporal en las deformaciones artificiales del cráneo se extiende geográficamente hasta el sudeste de la región pampeana (Berón y Baffi 2003; Perez 2006). Desde un punto de vista espacial, en el noreste de Patagonia y el sudeste de la región pampeana se encuentra representada la mayor variación en términos de "tipos" y "variedades" en relación con las regiones vecinas, mientras que al sur de los $48^{\circ}$ de Latitud Sur la frecuencia de esta práctica es muy baja (Bórmida 1953-54; Perez 2006).

Las deformaciones artificiales del cráneo en el centro este de Argentina (sudeste de Pampa y noreste 
de Patagonia) han sido extensamente investigadas a lo largo de los últimos 100 años, por el contrario los estudios desarrollados en el área noroeste de Patagonia resultan escasos. Hasta el presente los análisis morfológicos realizados sobre muestras de restos humanos procedentes de esta área se han limitado a la descripción de casos aislados y en consecuencia la variación presente resulta en gran medida desconocida (Mendonça et al. 1984-1985, 1988-1989; Sanguinetti de Bórmida 1981; Vayá 1981). El número de entierros recuperados ha crecido considerablemente como consecuencia del incremento de excavaciones arqueológicas sistemáticas y de rescate en sitios con restos óseos humanos (v.g. Biset 1989, Crivelli Montero et al. 1996; Cúneo y Della Negra 1999, Cúneo et al. 2002, Della Negra y Novellino 2002, 2005; Della Negra et al. 2008; Fernández 1991, Fernández y Panarello 2001; Hajduk y Biset 1991, 1996; Hajduk y Cúneo 1997-1998; Hajduk et al. 2000, Podestá y Pereda 1979). Las muestras recuperadas generalmente cuentan con información contextual y en numerosos casos con dataciones radiocarbónicas obtenidas directamente a partir de restos óseos humanos, por lo tanto son relevantes para el estudio de los patrones temporales y espaciales de variación en las deformaciones artificiales del cráneo. En este sentido, el presente trabajo tiene como objetivo analizar la variación en las deformaciones artificiales del cráneo presente en el noroeste de Patagonia, en particular en el norte y sur de la provincia de Neuquén e incorporarlas a la discusión acerca de los patrones de variación temporal y espacial a nivel supra-regional en Pampa y Patagonia.

\section{MATERIAL Y MÉTODOS}

\section{Muestras}

Los especímenes empleados en este trabajo corresponden a muestras de individuos adultos (Buikstra y Ubelaker 1994) de ambos sexos provenientes del noroeste de Patagonia, principalmente del norte de la provincia de Neuquén (Tabla 1), así como de varias muestras comparativas provenientes del sudeste de la región Pampeana, noreste y centro de Patagonia (Fig. 1; Tabla 2) (Bernal et al. 2008; Perez 2007). El sexo y la edad de los individuos estudiados fueron determinados a partir de caracteres morfológicos del cráneo y de la pelvis (Buikstra y Ubelaker 1994).
Los restos humanos del Noroeste de Patagonia analizados en este estudio proceden de los siguientes sitios arqueológicos:

Aquihuecó: el sitio se encuentra ubicado en

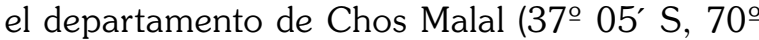
$22^{\prime}$ O) y esta emplazado en la parte superior de un médano. Este sitio, que se halla seriamente afectado por procesos de erosión, particularmente la eólica, muestra en lo funcional dos sectores: el de inhumaciones -al interior del cuerpo medanoso-, y el de paradero que refleja actividades variadas, localizado en una amplia superficie a sotavento del cuerpo medanoso. Durante los años 2003 y 20062007 se rescataron los restos humanos expuestos por la erosión y se excavaron entierros primarios tanto individuales como colectivos. El cálculo del NMI indicó la presencia de 56 individuos (Della Negra y Novellino 2005, Della Negra et al. 2008). Entre los escasos materiales directamente asociados a los entierros se encuentran bases de molinos, manos, cuentas de valva y un colgante de piedra (como parte de un collar). Un primer fechado radiocarbónico convencional, realizado sobre hueso humano dio 3.650 años AP (LP-1418) (Della Negra y Novellino 2005). Posteriormente tres fechados más, obtenidos por AMS sobre dos individuos brindaron las siguientes edades radiocarbónicas: $4.172 \pm 55$ AP (AA78839- X10646A/ AQ-I-Ind 23), $4.050 \pm 61 \mathrm{AP}$ (AA78840-X10647A /-AQ-IInd 22) y $3.817 \pm 59$ AP (AA78841- X10648A) AQ-I-Ind 16).

Tabla 1. Muestra de restos humanos procedentes de Neuquén analizados en este trabajo. El $\mathrm{N}$ de las muestras incluye individuos con y sin deformación artificial del cráneo.

\begin{tabular}{l|c|c|c} 
Sitio & Abr. & N & Años AP* \\
\hline Aquihuecó & AQH & 8 & 3.700 \\
\hline Hermanos Lazcano & HL & 4 & 3.800 \\
\hline Caepe Malal 1 & CM & 5 & $200-300$ \\
\hline Retamal 1 & SR & 1 & 600 \\
\hline Grande & SG & 1 & 670 \\
\hline Chacra Bustamante & Ch & 1 & 450 \\
\hline Loma de La Lata & LdL & 3 & $600-750$ \\
\hline Pocaullo & SP & 2 & $200-300$ \\
\hline Huechulafquen & H & 1 & $?$ \\
\hline Las Lagunas & LL & 2 & $?$
\end{tabular}

*Edad aproximada basada en fechados radiocarbónicos e información contextual. 


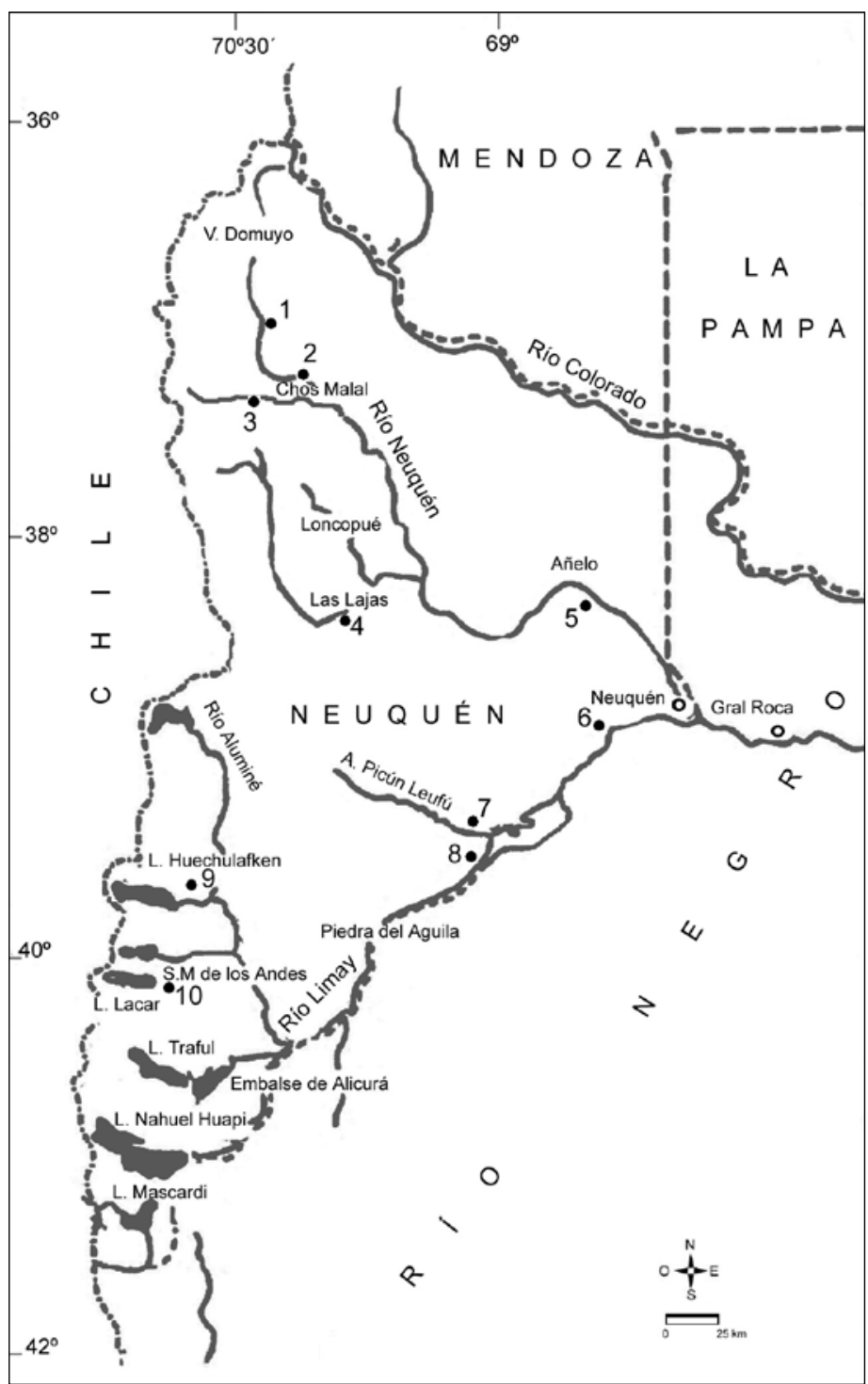

Fig. 1. Ubicación geográfica de los sitios arqueológicos de la provincia de Neuquén de los cuales proceden los individuos analizados: 1- Aquihuecó, 2 - Caepe Malal, 3- Hnos. Lazcano, 4- Las Lagunas, 5-

Loma de La Lata, 6- Retamal 1, 7- Chacra Bustamante, 8- Grande, 9- Huechulafquen, 10- Pocaullo.

Hermanos Lazcano: se encuentra ubicado en el valle del arroyo Chacay Melehue, departamento de Chos Malal (Cúneo y Della Negra 1999). El sitio se emplaza en un médano consolidado, con presencia de cubierta vegetal y con un sector parcialmente erosionado. En este último, la erosión dejó expuestos restos óseos de tres individuos, los cuales fueron rescatados en el año 1999 junto a algunos litos alargados de andesita de corte trapezoidal (Cúneo y Della Negra 1999, Della Negra
2005). La datación de uno de los individuos brindó la fecha de $3.780 \pm 50$ años radiocarbónicos AP (LP-1440). Durante el año 2008 se retomaron las excavaciones y se recuperó un número mínimo de 10 individuos, algunos asociados a adornos como colgantes y cuentas de valvas.

Caepe Malal: el sitio arqueológico Caepe Malal se encuentra ubicado en el departamento de Chos

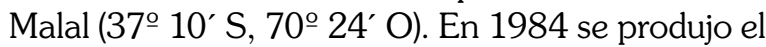


Tabla 2. Muestra de restos humanos utilizados en este trabajo para el análisis de la variación inter regional en las deformaciones artificiales del cráneo. El N de las muestras sólo incluye individuos con deformación artificial del cráneo. *Edad aproximada basada en fechados radiocarbónicos e información contextual.

\begin{tabular}{l|c|c|c|c}
\multicolumn{1}{c|}{ Muestras } & Abr. & Región Geográfica & Años AP* & N \\
\hline Sur de Mendoza & SM & Noroeste de Patagonia & $1.000-200$ & 13 \\
\hline Neuquén 1 & Nq1 & Noroeste de Patagonia & $4.000-3.500$ & 4 \\
\hline Neuquén 2 & Nq2 & Noroeste de Patagonia & $4.000-3.500$ & 4 \\
\hline Neuquén 3 & Nq3 & Noroeste de Patagonia & $1.000-200$ & 6 \\
\hline SE Pampa 1 & SEP1 & Sudeste de la Pampa & $2.500-2.000$ & 4 \\
\hline SE Pampa 2 & SEP2 & Sudeste de la Pampa & $1.000-200$ & 4 \\
\hline Río Negro 1 & RN1 & Noreste de Patagonia & 3.000 & 26 \\
\hline Río Negro 2 & RN2 & Noreste de Patagonia & 2.000 & 17 \\
\hline Río Negro 3 & RN3 & Noreste de Patagonia & $1.000-200$ & 18 \\
\hline San Blas & SB & Noreste de Patagonia & $1.000-200$ & 19 \\
\hline Isla Gama & IG & Noreste de Patagonia & $1.000-200$ & 10 \\
\hline San Antonio Oeste & SAO & Noreste de Patagonia & $2.500-2.000$ & 7 \\
\hline Río Chubut 1 & Ch1 & Centro de Patagonia & $2.000-1.500$ & 29 \\
\hline Río Chubut 2 & Ch2 & Centro de Patagonia & $1.000-200$ & 24 \\
\hline SO Chubut & SOCh & Centro de Patagonia & $1.000-200$ & 6 \\
\hline Total & & & & 178
\end{tabular}

hallazgo ocasional de un cementerio indígena que fue excavado por Adam Hajduk y Ana María Biset. Las primeras excavaciones sistemáticas se desarrollaron entre 1986 y 1991, relevándose 9 entierros humanos primarios tanto individuales como colectivos. En asociación con los individuos se hallaron, entre otros, recipientes de cerámica indígena (ollas y jarras), piezas metálicas (aros, punzones, frenos muleros, cuchillos, etc.), torteras líticas, cuentas vítreas, algunos fragmentos de textil y un fragmento de cuero pintado. Entre los restos faunísticos se encontraron restos de équidos, cánidos, ovi-cápridos y moluscos marinos (Hajduk 1991; Hajduk y Biset 1991, 1996). Posteriormente, en 1997 se recuperó un entierro secundario conformado por dos individuos y dos entierros primarios, en el cual una inhumación individual afectó en su integridad a otra preexistente subyacente (Hajduk et al. 2000; Della Negra 2005). Respecto a la cronología estimada para esta serie de inhumaciones, el análisis de las cuentas vítreas recuperadas, plantea su correspondencia a mediados del siglo XVIII (Hajduk 1991).

Grande: el sitio fue excavado en 1997, se encuentra ubicado en una isla del curso medio del río Limay, en el departamento de Picún Leufú (39ํ5'의, $69^{\circ} 1^{\prime}$ O). Se halló un entierro formado por un número mínimo de tres individuos (Della Negra y Novellino 2002). Asociado a los mismos se recuperó material cerámico decorado y no decorado así como material lítico, puntas de proyectil pedunculadas y apedunculadas, instrumentos de doble filo, un fragmento de mano y una base de molino, un colgante de madera, piedras con incisiones y cuentas de valva y hueso (Della Negra y Novellino 2002). Se realizó un fechado radiocarbónico AMS, sobre colágeno humano, dando como resultado una antigüedad de $670 \pm 40$ años radiocarbónicos AP (UGA № 9209) (Della Negra ms.; Della Negra et al. 2002; Della Negra 2005).

Pocaullo: este sitio se encuentra en San Martín

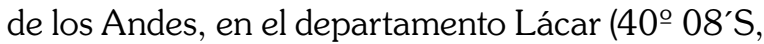

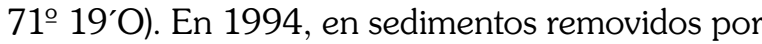
máquinas retroexcavadoras afectadas a una obra de construcción, se observaron y recuperaron un conjunto de huesos humanos junto con restos de recipientes cerámicos y una pipa lítica. Los estudios realizados estimaron la probable relación contextual de los restos entre sí (Hajduk y Cúneo 1997-1998). Los restos humanos corresponden a cuatro individuos. Entre los fragmentos de recipientes cerámicos rescatados, se destacan dos jarritas que fueron reconstruidas en laboratorio, más fragmentos de otra, que presentan decoración pintada. Esta decoración las hace asignables al tipo cerámico Valdivia. Considerando estas piezas decoradas, se estimó que el conjunto arqueológico rescatado correspondería probablemente al siglo XVIII. 
Sitio Retamal 1 (o Neuquén del medio): el sitio se encuentra ubicado en el departamento Confluencia (38 $\left.59^{\prime} \mathrm{S}, 68^{\circ} 43^{\prime} \mathrm{O}\right)$. Se halló un individuo en posición flexionada asociado a una punta de proyectil bifacial apedunculada (Della Negra ms.). A partir de un fechado radiocarbónico, se estableció una antigüedad de $190 \pm 60$ años radiocarbónicos AP (LP1689) para este individuo (Della Negra ms; Della Negra 2005).

Chacra Bustamante: este sitio se encuentra en la Chacra Bustamante (39 $30^{\prime} \mathrm{S}, 69^{\circ}$ 30’ O), en el departamento de Picún Leufú. Fue excavado en 1992 por Estela Cúneo quien realizó el rescate de un entierro de un individuo masculino de entre 45 y 50 años de edad que se encontraba en posición fetal y con los miembros inferiores flexionados sobre el pecho (Cúneo et al. 2002). Los materiales asociados consistieron en puntas de proyectil de pequeño tamaño, de limbo triangular y bases escotadas y rectas, instrumental óseo, cerámica lisa y decorada, raspadores de variada morfología e instrumental de molienda. El fechado radiocarbónico convencional dio por resultado $450 \pm 40$ años radiocarbónicos AP (UGA-9208) (Cúneo et al. 2002: 16).

Loma de la Lata: el sitio esta ubicado en el departamento Confluencia (38 $25^{\prime}$ S, 68 $41^{\prime}$ O). En el mismo fueron excavados entierros primarios y secundarios de un número mínimo de 27 individuos de ambos sexos. Los entierros se encontraron cubiertos por piedras laja. Se hallaron además puntas de proyectil de limbo triangular alargado y bases cóncavas, tembetás, valvas perforadas, collares confeccionados con caracoles, cuentas realizadas con valvas de moluscos y con rocas de color verdeazuladas que contienen minerales de cobre (posiblemente crisocola). El sitio aun no fue excavado en su totalidad (Biset 1989; Della Negra 2005). Dos fechados radiocarbónicos efectuados por AMS sobre restos óseos de dos individuos dieron por resultado $600 \pm 60$ años radiocarbónicos AP (UGA\#11669) y $740 \pm 40$ años radiocarbónicos AP (UGA\#12318).

Huechulafquen: Se trata de un entierro individual hallado en superficie, sobre un médano en el

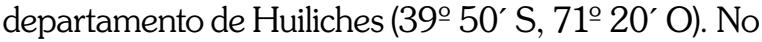
se encontró material arqueológico asociado al individuo y aún no se dispone de fechados radiocarbónicos.
Las Lagunas: El sitio se encuentra ubicado en la Estancia Llamuco, a $100 \mathrm{~km}$ de la ciudad de Zapala, en el Departamento de Zapala. El entierro fue excavado por Isabel Pereda en el año 1977. Se encontraron los restos de cuatro esqueletos (Mendonça et al 1984-85: 237). Los mismos fueron hallados en sedimentos arcillosos, por debajo de otros más arenosos, a escasa profundidad. El primer esqueleto, denominado NLE-1, se encontraba en posición decúbito lateral izquierdo, flexionado, con el rostro hacia el oeste. Es un varón adulto, de aproximadamente 30 años de edad y de una talla de $1,617 \mathrm{~m}$. El esqueleto designado NLE-2, fue encontrado en posición decúbito dorsal, con las piernas flexionadas sobre el costado lateral izquierdo. Este esqueleto estaba asociado a tres instrumentos bifaciales de obsidiana y cuentas de valvas de moluscos en la porción cervical. Se trata de un individuo femenino de 22 a 25 años y con una talla estimada de 1,561 $\mathrm{mm}$. El esqueleto NLE-2 se trata también de un individuo femenino de aproximadamente 25 años. El esqueleto NLE-3 fue enterrado en posición decúbito lateral izquierdo, se trata de un masculino adulto de más de 45 años. (Mendonça et al. 1988-1989:59.).

\section{Análisis morfométricos y estadísticos}

Para estudiar la variación en las deformaciones artificiales se analizaron coordenadas de 2 landmarks ( $\square$ ) y 78 semilandmarks $(0)$ registrados sobre imágenes digitales del cráneo obtenidas en norma lateral (Fig. 2). Las imágenes fueron obtenidas con los cráneos posicionados en el plano de Frankfurt utilizando una cámara digital Olympus SP 350. Las imágenes de los individuos fueron procesadas con el programa MakeFan6 (Sheets 2003), que permite la colocación de líneas con un mismo desplazamiento angular (i.e. fans) a lo largo de un contorno, lo cual posibilita un espaciamiento más regular de las coordenadas de los semilandmarks. Las coordenadas de landmarks y semilandmarks fueron registradas empleando el programa tpsDIG 1.40 (Rohlf, 2008).

Las coordenadas de landmarks y semilandmarks fueron superpuestas utilizando el Análisis Procrustes Generalizado (Generalized Procrustes Analysis; Rohlf y Slice 1990) y, a su vez, los semilandmarks fueron deslizados a lo largo del contorno por medio del criterio de distancia Procrustes mínima (Bookstein et al. 2002; Perez et al. 2006). La fun- 


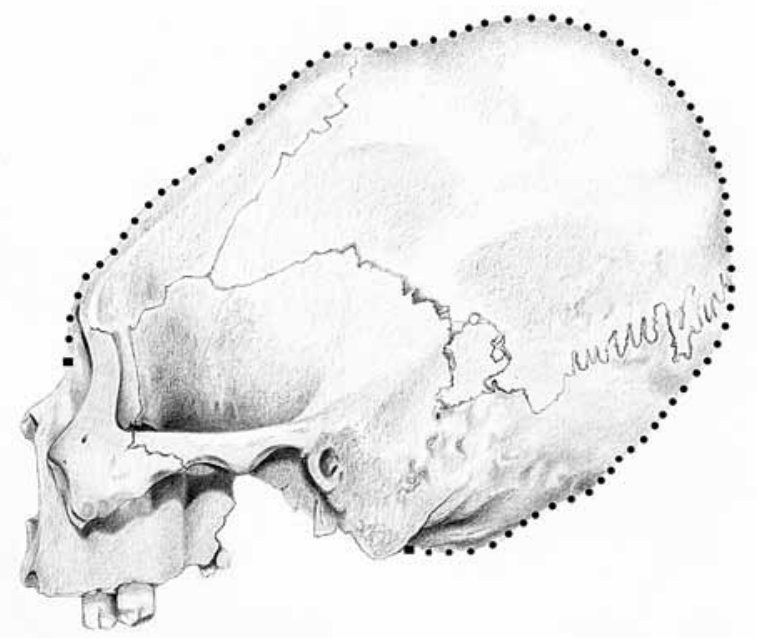

Fig. 2. Landmarks y semilandmarks registrados sobre imágenes digitales del cráneo obtenidas en norma lateral.

ción thin-plate spline fue utilizada para mapear las diferencias entre los especímenes y la referencia, en un espacio tangente al generado por la superposición Procrustes (Rohlf 1999; Slice 2001), y de este modo obtener un conjunto de variables de forma (partial warps y vectores del componente uniforme; Bookstein 1989, 1991). Un análisis de Relative Warps (RW) o Componentes Principales, efectuado a partir de los partial warps y de los vectores del componente uniforme (Bookstein 1991; Rohlf 1993), fue empleado para comparar las configuraciones de landmarks y semilandmarks. Los programas Semiland6 (Sheets 2003) y tpsRelw 1.44 (Rohlf 2008) fueron usados para superponer las coordenadas de landmarks y semilandmarks. Los partial warps, los vectores de variación uniforme, así como los componentes principales obtenidos a partir de los mismos, fueron calculados por medio del programa tpsRelw 1.44 (Rohlf 2008). El parámetro alfa fue usado con un valor de 0, lo cual permite incluir todas las escalas geométricas de variación (Rohlf 1993, 1996).

En primer lugar, para la muestra de Neuquén (Tabla 1) se calcularon relative warps con el fin de describir la variación en el contorno del esqueleto neurocraneal relacionada con la deformación artificial. Los scores de los relative warps describen los ejes ortogonales de mayor variación en la muestra. Dentro de una muestra que contiene individuos con y sin deformación, el primer eje representa el "eje de deformación" en base al cual fueron determinados los individuos deformados y no deformados (Colantonio y Marcellino 1996; Perez 2006, 2007). Esta aproximación fue empleada previamente para diferenciar los individuos deformados y no deformados para las otras muestras estudiadas en este trabajo (Perez 2006, 2007). En particular, en aquellas muestras que presentaron una distribución discontinua a lo largo del primer RW se empleo esta discontinuidad para separar individuos deformados de no deformados. En cambio, cuando la distribución de los individuos es continua se exploró la variación en forma en las grillas de deformación calculadas a lo largo del RW1 y en función de esto se estableció un punto de corte entre estos dos grupos (Perez 2006, 2007). En las muestras en las cuales los individuos deformados no se separan "naturalmente" en el espacio multivariado de los no deformados esta aproximación evita la subjetividad de generar visualmente una serie de cambio en forma, pero no evita tomar una decisión acerca de en que punto se encuentra la transición entre estos dos grupos.

Finalmente se comparó la variación interregional en las deformaciones artificiales del cráneo mediante el cálculo de relative warps para los consensos (o formas medias) de los landmarks y semilandmarks en norma lateral. Los scores de los relative warps fueron empleados para estudiar la asociación entre las deformaciones craneanas y la variación temporal entre las muestras. Con este fin se realizó un análisis Procrustes (PROTEST) (PeresNeto y Jackson 2001). El estadístico Procrustes ha sido propuesto para comparar conjuntos de datos multivariados en lugar de la prueba de Mantel, ampliamente usada en estudios de ecología y evolución (Peres-Neto y Jackson 2001). Los análisis comparativos de ambas pruebas han mostrado que PROTEST es tanto o más poderoso que la prueba de Mantel para detectar asociaciones de matrices en circunstancias variadas (ver Peres-Neto y Jackson 2001). Para realizar el análisis de Procrustes se procede del siguiente modo: a) las ordenaciones en varias dimensiones son escaladas y rotadas con el fin de encontrar una superposición óptima que maximice su ajuste; b) la potencia cuadrada de la suma de los residuos (ss) entre configuraciones en su superposición óptima puede ser usada como una métrica de asociación $\left[m_{12}=\left(\sum 1-s s\right)^{2}\right.$; Gower 1971 ; Peres-Neto y Jackson 2001]; y c) un procedimiento de permutación (n: 10.000) (PROTEST) fue usado 


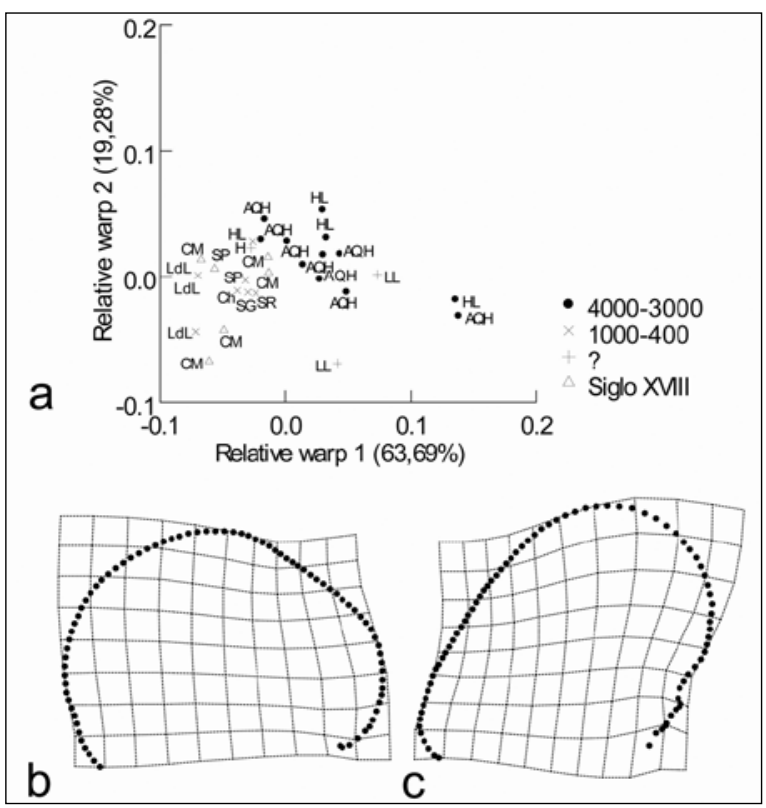

Fig. 3. Análisis de relative warps (RW) realizado a partir de las variables registradas en el cráneo en norma lateral (a) procedentes de los sitios arqueológicos de Neuquén. Las grillas de deformación (b y c) representan los cambios en forma en los extremos negativo y positivo del primer eje.

para conocer la significación estadística del ajuste Procrustes (Peres-Neto y Jackson 2001). Los análisis de Procrustes y PROTEST fueron efectuados usando el paquete vegan 1.4.4 para $\mathrm{R} 2.8 .1$ (RDevelopmental Team 2008).

\section{RESULTADOS}

En la Fig. 3 se presenta la variación morfológica en el contorno craneal de las muestras de Neuquén resumida en los dos primeros relative warps. A lo largo del primer RW $(63,69 \%)$ se observa una distribución continua cuya variación es atribuible a la deformación artificial del cráneo. Los individuos de Loma de La Lata y Caepe Malal, ubicados en el extremo negativo del primer eje, presentan una deformación caracterizada por una expansión en la región del hueso frontal y la compresión en la región del lambda (Fig. 3b). Por otro lado, los individuos de los sitios Aquihuecó, Las Lagunas y Hermanos Lazcano, ubicados hacia los valores positivos del eje, presentan una compresión en la región del hueso occipital y otra en el frontal (Fig. 3c). Esta variación en forma está relacionada con las diferencias temporales

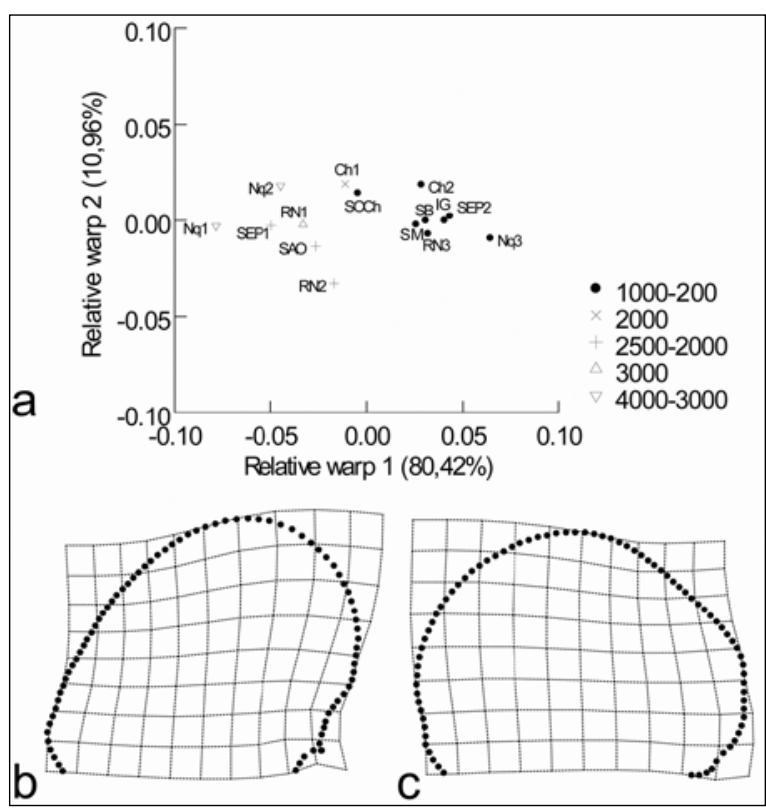

Fig. 4. Análisis de relative warps (RW) realizado a partir de las variables registradas en el cráneo en norma lateral (a) procedentes de los sitios arqueológicos de Neuquén, del Noreste y centro de Patagonia y sur de Pampa. Las grillas de deformación (b y c) representan los cambios en forma en los extremos negativo y positivo del primer eje.

entre los individuos estudiados. Las deformaciones con modificaciones en la región del lambda son las más tardías, mientras que las formas que presentan una compresión en la región occipital y otra en el frontal están datadas en el Holoceno tardío inicial (Fig. 3; Tabla 1).

A partir de la ordenación de los individuos a lo largo del RW 1 se separaron tres grupos de deformaciones $\mathrm{Nq} 1, \mathrm{Nq} 2$ y Nq3 de acuerdo con la similitud morfológica. El grupo Nq1 representa los individuos con la mayor compresión en la región occipital y en el frontal, el grupo Nq3 esta formado por los individuos con modificaciones concentradas en la región del lambda, mientras que el grupo Nq2 esta constituido por los individuos con modificaciones en región occipital y frontal pero con formas intermedias entre estos dos últimos grupos.

En la Fig. 4 se presentan las diferencias en forma entre las medias de los individuos deformados en las muestras del norte y centro de Patagonia correspondientes a distintos periodos temporales. Los extremos de variación a lo largo del primer relative warp $(80,42 \%)$ corresponden con deformaciones caracterizadas por una compresión en la región del 
lambda y una expansión en el frontal en el extremo positivo del eje (Fig. 4b), y deformaciones que presentan una compresión tanto en la región occipital como en la frontal hacia el extremo negativo (Fig. $4 \mathrm{c}$ ). A nivel supra-regional puede observarse la misma tendencia en la variación morfológica que esta presente en la muestra de Neuquén. Así como en esta última región, la variación en forma esta relacionada con las diferencias temporales entre las muestras estudiadas.

Finalmente, el valor de $m_{12}$ (pseudo-correlación) entre la ordenación de los dos primeros relative warps y las diferencias temporales entre las muestras estudiadas fue muy alto y significativo $\left(m_{12}=\right.$ $0.8598, \mathrm{P}<0.0001$, basado en 10.000 permutaciones). Este resultado confirma la concordancia entre la variación en la forma de las deformaciones artificiales del cráneo y las diferencias temporales entre las muestras analizadas.

\section{DISCUSIÓN Y CONCLUSIONES}

La variación en las deformaciones artificiales del cráneo en Neuquén presenta un marcado patrón temporal. En los sitios más antiguos, asignables al límite Holoceno medio-tardío (ca 4.000 años AP) se encuentran deformaciones caracterizadas por compresión en la región occipital y en el frontal (i.e. los tipos circular y/o pseudocircular de Imbelloni 1924-25; ver Mendonça et al. 1988-89 para una mayor discusión de este tema). Formas similares se encuentran en los entierros del litoral atlántico del norte de Patagonia estudiados por Marcelo Bórmida (1950) y datados en ca 3.000 años AP (Bernal et al. 2008), y en el sudeste de la Región Pampeana (Perez 2006). Los resultados alcanzados en este trabajo amplían la distribución geográfica de esta deformación poniendo de relieve la dispersión supra-regional de estos rasgos culturales. Asimismo, extiende la profundidad temporal de las deformaciones artificiales en el norte de Patagonia hasta el límite Holoceno medio-tardío.

Esta modificación de la morfología craneana puede estar relacionada con prácticas intencionales, efectuadas mediante la aplicación de elementos deformatorios tales como vendas (Brothwell 1981; Buikstra y Ubelaker 1994; Dembo y Imbelloni 1938). En el sitio Arroyo Seco 2, al sudeste de la Región Pampeana, se han encontrado deformaciones similares con dataciones en ca 7.000 años AP (ver Perez 2006). Se ha planteado que las deformaciones intencionales serían reflejo del tiempo y el esfuerzo realizado para lograr una forma craneana predeterminada, la cual es generalmente usada como un indicador de identidad grupal, demarcador de fronteras territoriales o sociales, o como un rasgo que refuerza y mantiene las redes de intercambio entre grupos (Blom 2005; Getszten 1993; Munizaga 1992; Torres-Rouff 2002, 2003). Si bien estudios previos vinculaban este tipo de deformación al desarrollo de las jerarquías en sociedades de tipo jefatura o estado (Bórmida 1953-54; Dembo e Imbelloni 1938; Imbelloni 1924-25), su presencia en grupos cazadores recolectores y la antigüedad de los fechados en el noroeste de Patagonia señalan la necesidad de investigar el significado social de tales prácticas en estas sociedades.

La deformación caracterizada por la compresión en la zona del lambda y expansión del frontal (correspondiente con el grupo Tabular erecto plano-lámbdico de Imbelloni 1924-25) presente en el Holoceno tardío final de Neuquén (ca 500 años AP; Della Negra y Novellino 2005, Della Negra et al. 2008) se encuentra también en la desembocadura del Río Negro, San Blas, Isla Gama, sur de Mendoza y, aunque más leve, en la desembocadura del Río Chubut. Diferentes fechados establecidos para el sudeste de la Región Pampeana (Barrientos 1997; Madrid y Barrientos 2000; Oliva et al. 1991), el Río Colorado (Martínez 2002, 2004; Martínez y Figuerero Torres 2000), el Río Negro (Bernal et al. 2008), sur de Mendoza (Gil et al. 2006; Novellino 2002), La Pampa (Berón y Baffi 2003) y Chubut (Gómez Otero y Dahinten 1997-1998), así como los contextos de excavación (Bórmida 1950; Barrientos 1997, 2001; Outes 1907; Vignati 1931), establecen que estas últimas morfologías asignables a deformaciones artificiales corresponden al Holoceno tardío final (ca 400 - 1.500 años AP).

Esta deformación se relaciona generalmente con la aplicación de una banda para atar o sujetar a los niños a las cunas; esto constituye una práctica frecuente en grupos cazadores recolectores con alta movilidad ya que facilita el traslado de los niños. En Neuquén, particularmente, hay evidencia arqueológica y etnohistórica de esta práctica (Crivelli Montero et al. 1996; Hilger 1957). Las excavaciones realizadas durante los años 1988 -1992 en la cueva Epullán 
Grande (cuenca media del río Limay) permitieron hallar en los estratos 1 y 2 una inhumación conteniendo un individuo infantil envuelto en una manta de cueros cosidos de guanaco. La misma fue asignada a tiempos post hispánicos. El cuerpo estaba envuelto en el quillango asegurado a una cuna, la que consistía de una plataforma o espaldar de medias cañas de Chusquea Culeou (colihue) y presentaba ganchos de amarre probablemente vacuno o equino. Las fuentes etnohistóricas no mencionan prácticas intencionales de deformación del cráneo; sin embargo, existen referencias sobre el uso de cunas. Luis de la Cruz señala que Para criar los chicos mantienen un cajoncillo de tablillas amarradas, que llaman dichas. Ahí dentro ponen unos pellejos de pieles de carnero, envuelven a la criatura en una mantilla de bayeta, con una faja les atan por encima de los brazos, y a los pies les dan otra ligadura y así lo echan a la dicha, a la que vuelven a atarlo. De esta suerte se cuelga el cajoncillo a la espalda y andan con él por todas partes que se les ofrece, a pie o a caballo (de la Cruz [1806] 1969:485). Asimismo, Felipe Gómez de Vidaurre (1889) señala que durante los siglos XVII al XIX los Araucanos colocaban a los niños sobre pieles en una cuna llamada chigua, que tenía forma de cajón o de cesto y que se colgaba de las vigas del techo de la ruka con un cordel o correas. Además usaban como cuna portátil, el cupülhue. El pequeño se mantenía en postura vertical, convenientemente envuelto en mantas, con los brazos libres. Esta cuna se usaba cuando las mujeres salían de la casa llevándose consigo las criaturas. Para tener los brazos libres, la madre llevaba el cupülhue en su espalda, suspendido de la frente por una correa. Para descansar, lo sacaba y lo dejaba parado, ligeramente inclinado hacia atrás y apoyado contra un árbol. Este aparato se usaba hasta que los niños aprendían a andar.

Es importante destacar que la distribución geográfica de esta deformación plano-lámdica en Sudamérica es acotada a la distribución de los grupos cazadores recolectores del norte de Patagonia, sur de Cuyo y al sudeste de la Región Pampeana (ver Perez 2007). Las deformaciones presentes en el Holoceno tardío final en los grupos agricultores del noroeste Argentino presentan características marcadamente diferentes (Perez 2006, 2007).

Finalmente, las muestras que presentan morfologías intermedias a las mencionadas en los párrafos anteriores, caracterizadas por una compresión antero-posterior oblicua con frontal y occipital planos (Fig. 4), sólo se encuentran en el noreste de Patagonia. Estas deformaciones corresponden con el tipo tabular oblicuo de Imbelloni (1924-25) y han sido fechadas en el Holoceno tardío inicial (Bernal et al. 2008; Berón y Baffi 2003). Una posición cronológica similar a estos últimos tienen los cráneos con una leve deformación del frontal del valle del Río Chubut (probablemente correspondiente con el grupo Tabular erecto plano-frontal de Imbelloni 1924-25; Gómez Otero y Dahinten 1997-98). Esta modificación craneofacial también podría ser realizada de manera intencional mediante la aplicación de elementos deformatorios tales como vendas y tablillas (Brothwell 1981; Buikstra y Ubelaker 1994; Dembo y Imbelloni 1938). La misma, se encuentra distribuida en la región de los Andes centrales, con dataciones principalmente en el Holoceno tardío.

En síntesis, Neuquén presenta un patrón de variación en las deformaciones artificiales del cráneo similar al noreste de Patagonia y el sudeste de la Región Pampeana. Una característica interesante de estas regiones es que las deformaciones más antiguas podrían ser intencionales mientras que las correspondientes al Holoceno tardío final están relacionadas al uso de cunas. Las primeras, en particular, han sido vinculadas al surgimiento de diferencias sociales o étnicas marcadas (Blom 2005; Torres-Rouff 2003). Sin embargo, estas deformaciones en el noroeste de Patagonia podrían estar relacionadas con otros procesos socio-culturales ocurridos en la región, por ejemplo el surgimiento de territorialidad. En cualquier caso, los resultados obtenidos muestran que las deformaciones circular y tabular oblicua no estarían universalmente relacionadas a la aparición de estados y jefaturas, y ya estarían presentes en los cazadores recolectores del Holoceno medio-temprano de Pampa y del Holoceno medio-tardío del norte de Patagonia (v.g. sitios Arroyo Seco 2, Aquihuecó).

Los resultados presentados han permitido incrementar la comprensión de los patrones de variación en el registro arqueológico del noroeste de Patagonia. La integración de la información aquí analizada con otra proveniente de múltiples líneas de evidencia arqueológica (v.g. tecnológica, estilística) contribuirá a profundizar en el conocimiento de la dinámica socio-cultural, a inferir procesos genera- 
dores, así como los mecanismos de transmisión y mantenimiento de los rasgos culturales a distintas escalas temporales y espaciales en Patagonia.

\section{AGRADECIMIENTOS}

Queremos agradecer a Héctor M. Pucciarelli (División Antropología, FCNyM, UNLP), Inés Baffi y Leandro Luna (Museo Etnográfico "J. B. Ambrosetti", FFyL, UBA) por facilitar el acceso a las colecciones de los museos a su cargo.

\section{BIBLIOGRAFÍA}

BARRIENTOS, G. 1997. Nutrición y dieta de las poblaciones aborígenes prehispánicas del Sudeste de la Región Pampeana. Tesis doctoral inédita, Universidad Nacional de La Plata, La Plata. MS.

BARRIENTOS, G. 2001. Una aproximación bioarqueológica al estudio del poblamiento prehispánico tardío del Sudeste de la Región Pampeana. Intersecciones en Antropología 2:3-18

BERNAL, V., P.N. GONZALEZ, S.I. PEREZ y H.M. PUCCIARELLI. 2008. Entierros humanos del noreste de Patagonia: nuevos fechados radiocarbónicos. Magallania 36 (2): 175-183.

BERÓN, M. A. y E. I. BAFFI. 2003. Procesos de cambio cultural en los cazadores-recolectores de la provincia de La Pampa, Argentina. Intersecciones en Antropología 4:29-43.

BISET, A. M. 1989. Rescate de un cementerio indígena en Añelo, provincia del Neuquén. I Jornadas-Taller sobre El uso del pasado, Simposio Administración de Bienes Culturales. Facultad de Ciencias Naturales y Museo de la Universidad Nacional de La Plata, La Plata.

BLOM, D.E. 2005. A bioarchaeological approach to Tiwanaku group dynamics. En: Us and Them: Archaeology and Ethnicity in the Andes, R. Reycraft (Editor). pp. 153-182. Cotsen Institute of Archaeology Press, Los Angles CA.

BOOKSTEIN, F.L. 1989. Principal warps: Thin-plate splines and the decomposition of deformations. IEEE Transactions on Pattern Analysis and Machine Intelligence 11: 567-585.

BOOKSTEIN, F.L. 1991. Morphometric Tools for landmark data: geometry and biology. Cambridge, Cambridge University Press.

BOOKSTEIN, F.L., A.P. STREISSGUTH, P.D. SAMPSON, P.D. CONNOR, y H.M. BARR. 2002. Corpus callosum shape and neuropsychological deficits in adult males with heavy fetal alcohol exposure. NeuroImage 15:233-251.
BÓRMIDA, M. 1950. Cementerios indígenas prehispánicos en la zona de la Laguna del Juncal. Anales del Museo Nahuel Huapi 2:101-108.

BÓRMIDA, M. 1953-54. Los antiguos Patagones. Estudio de craneología. Runa VI (1-2):55-96.

BROTHWELL, D.R., 1981. Digging Up Bones. Cornell University Press, New York.

BUIKSTRA, J y D. UBELAKER. 1994. Standards for data collection from human skeletal remains. Arkansas Archaeological Survey Research Series 44.

COCILOVO, J. A. 1973. Dimorfismo sexual y deformación craneana artificial en patagones de Chubut. Córdoba, Actas II Simposio Internacional de Ciencias Morfológicas, pp. 632-644.

COLANTONIO, S. y A. MARCELLINO. 1996. Influencia del tamaño y la deformación artificial en las comparaciones morfológicas de cráneos de aborígenes. Buenos Aires, Resúmenes de las 2das Jornadas Nacionales de Antropología Biológica, pp. 132.

CRIVELLI MONTERO, E., U. PARDIÑAS, M. FERNÁNDEZ, M. BOGAZZI, A. CHAUVIN, V. FERNÁNDEZ, y M. LEZCANO. 1996. La cueva Epullán Grande (provincia del Neuquén). Informe de Avance. Praehistoria 2:185265, PREP-CONICET. Buenos Aires.

CÚNEO, E. M. y C. DELLA NEGRA. 1999. Rescate arqueológico en el sitio Hermanos Lazcano (paraje Chacay Melehue, cuenca del Curi Leuvú, departamento Chos Malal). Informe presentado a la Dirección General de Cultura de la Provincia del Neuquén. MS.

CÚNEO, E., C. DELLA NEGRA, y P. NOVELLINO. 2002. Tres sitios con restos óseos humanos en la cuenca del arroyo Picún Leufú (departamentos Picún Leufú y Catan Lil, provincia del Neuquén). Libro de resúmenes. Quintas Jornadas de Arqueología de la Patagonia. Buenos Aires. pp. 16.

DE LA CRUZ, L. 1969 [1806]. Viaje a su costa del alcalde provincial del muy ilustre Cabildo de la Concepción de Chile, don Luis De la Cruz. Desde el fuerte de Ballenar hasta Buenos Aires. Pedro de Angelis (compilador) Colección de Obras y Documentos relativos a la historia antigua y moderna de las provincias del Río de la Plata, II: Plus Ultra, Buenos Aires.

DELLA NEGRA, C. 2005. Sitios arqueológicos con restos óseos humanos en la provincia del Neuquén, su relevancia y análisis comparativo. Libro de resúmenes. Actas IV Congreso Regional de Historia del Neuquén. Junin de los Andes agosto 2005.

DELLA NEGRA, C., y P. NOVELLINO. 2002. Nuevos estudios sobre los antiguos habitantes de la cuenca el rio Limay: 
sitio Grande, Departamento Picun Leufu, Provincia del Neuquén. Relaciones de la Sociedad Argentina de Antropología 27:101-113.

DELLA NEGRA, C., NOVELLINO, P. y SCIANCA S.; Nuevos aportes a la arqueología de la cuenca del río Limay, 2002, Actas II Congreso de Historia del Neuquén- Junín de los Andes- Agosto 2002.

DELLA NEGRA, C., y P. NOVELLINO. 2005. Aquihuecó: un cementerio arqueológico en el norte de la Patagonia, valle del Curi Leuvú, Neuquén, Argentina. Magallania. 33(2):165-172.

DELLA NEGRA, C., NOVELLINO P., PEREZ S.I., HAJDUK A. y V. BERNAL. 2008. Investigaciones arqueológicas y bioarqueológicas en el sitio Aquihueco (Norpatagonia): nuevos resultados. Actas VII Jornadas de Arqueología de la Patagonia. En prensa.

DEMBO, A. y J. IMBELLONI. 1938. Deformaciones intencionales del cráneo de carácter étnico. Buenos Aires, J. Anesi.

FERNÁNDEZ, J. 1991. La cueva de Haichol. Arqueología de los pinares cordilleranos del Neuquén. Anales de Arqueología y Etnología (1988-1990), 43/45 (1-3):1-740. Universidad Nacional de Cuyo. Mendoza.

FERNÁNDEZ, J. y H. PANARELLO. 2001. Cazadores recolectores del Holoceno Medio y Superior de la Cueva Haichol, región cordillerana central del Neuquén, República Argentina. Relaciones de la Sociedad Argentina de Antropología, XXVI: 9-30.

GETSZTEN, P.C. 1993. An investigation into the practice of cranial deformation among the pre-Columbian peoples of northern Chile. International Journal of Osteoarchaeology 3: 87-98.

GIL, A., R. TYKOT, G. NEME, y M. SHELNUT. 2006. Maize on the frontier. Isotopic and macrobotanical data from Central-Western Argentina. En: Histories of maize multidisciplinary approaches to the prehistory, biogeography, domestication, and evolution of maize, J. Staller, R. Tykot, B. Benz (editores). pp 199-214. Academic Press. New York.

GÓMEZ DE VIDAURRE F. 1889. Historia geográfica, natural y civil del Reino de Chile. Colección de historiadores de Chile. Santiago.

GOMEZ OTERO, J. y S. DAHINTEN. 1997-1998. Costumbres funerarias y esqueletos humanos: variabilidad y poblamiento en la costa Nordeste de la Provincia del Chubut (Patagonia Argentina). Relaciones de la Sociedad Argentina de Antropología. 22-23:101-124.

GOWER, J.C. 1971. Statistical methods of comparing different multivariate analyses of the same data. En: Hodson FR, Kendall DG y Tautu P (eds): Mathematics in the archaeological and historical sciences. Edinburgh, Edinburgh University Press, pp. 138-149.

HAJDUK, A. 1991. Las cuentas vítreas del sitio arqueológico Caepe Malal I (Departamento. Chos Malal, Neuquén) como indicadores temporales. En: Boschín, M. T. (compiladora) Cuadernos de investigación. Arqueología y Etnohistoria de la Patagonia Septentrional, pp. 36-48, Tandil, IEHS.

HAJDUK, A., y A. M. BISET. 1991. Principales características del sitio Caepe Malal I, Valle del río Curi Leuvú, Departamento Chos Malal (Provincia del Neuquén). Informe preliminar. En: Boschín, M. T. (compiladora) Cuadernos de investigación. Arqueología y Etnohistoria de la Patagonia Septentrional, pp. 6-17, Tandil, IEHS.

HAJDUK, A., y A. M. BISET. 1996. El sitio arqueológico Caepe Malal I (cuenca del río Curi Leuvú, Departamento Chos Malal, Provincia del Neuquén). En: Arqueología. Sólo Patagonia, J. Gómez Otero (compiladora), pp. 77-87, CENPAT-CONICET, Puerto Madryn.

HAJDUK, A., y E. M. CÚNEO. 1997-1998. Rescate arqueológico en San Martín de los Andes (departamento Lácar, provincia del Neuquén) y algunas reflexiones acerca de la cerámica con decoración valdiviana. Relaciones de la Sociedad Argentina de Antropología XXII-XXIII:319-342.

HAJDUK, A., E. M. CÚNEO; A .M. ALBORNOZ, C. DELLA NEGRA, y P. S. NOVELLINO. 2000. Nuevas investigaciones desarrolladas en el sitio Caepe Malal I (cuenca del Curi Leuvú, departamento Chos Malal, provincia del Neuquén). En: Desde el País de los Gigantes. Perspectivas arqueológicas en Patagonia, F. Carballo Marina, J. B. Belardi y S. Espinosa (editores) tomo 1, pp. 297-313, UNPA, Río Gallegos.

HILGER, I. 1957. Araucanian Childlife and its Cultural Background. Smithsonian Miscellaneous Collections, Washington, D.C.

IMBELLONI, J. 1923. Introducción a nuevos estudios de craneotrigonometría. Anales del Museo Nacional de Historia Natural 31:31-94.

IMBELLONI, J. 1924-25. Deformaciones intencionales del cráneo en Sud América. Revista del Museo de La Plata. 28:329-407.

MADRID, P. y G. BARRIENTOS. 2000. La estructura del registro arqueológico del sitio Laguna Tres Reyes 1 (Provincia de Buenos Aires): Nuevos datos para la interpretación del poblamiento humano del Sudeste de la Región Pampeana a inicios del Holoceno tardío. Relaciones de la Sociedad Argentina de Antropología 25:179-206.

MARTINEZ, G. 2002. Cronología y análisis isotópicos de los entierros humanos del sitio La Petrona (Pdo. de Villarino, 
pcia. de Buenos Aires). Libro de Resúmenes del Tercer Congreso de Arqueología de la Región Pampeana Argentina, Olavaria. pp. 25.

MARTINEZ, G. 2004. Resultados Preliminares de las investigaciones arqueológicas realizadas en el curso inferior del río Colorado (Pdos. de Villarino y Patagones). En: Aproximaciones Contemporáneas a la Arqueología Pampeana, G. Martínez, M. Gutierrez, R. Curtoni, M. Berón, P. Madrid (editores). pp. 275-292. Facultad de Ciencias Sociales (UNCPBA). Olavaria.

MARTINEZ, G. y M. J. FIGUERERO TORRES. 2000. Sitio arqueológico La Petrona (Partido de Villarino, provincia de Buenos Aires): Análisis de las modalidades de entierro en el área sur pampeana. Relaciones de la Sociedad Argentina de Antropología 25:227-248.

MENDONÇA, O, J. COCILOVO, e I. PEREDA. 1984-1985. Observaciones de interés tafonómico en los restos óseos humanos del sitio "Las Lagunas" (Provincia del Neuquén). Relaciones de la Sociedad Argentina de Antropología, Nueva Serie, XVI:235-248.

MENDOÇA, O, M. BORDACH, y A. R. CIGNETTI. 1988-1989. Deformación craneana en Las Lagunas (Neuquén). Viejas y nuevas cuestiones sobre la variante pseudocircular. Relaciones de la Sociedad Argentina de Antropología, Nueva Serie, XVII/2:57-73.

MUNIZAGA, J.R. 1992. Antropología física de los Andes del Sur. En: Prehistoria Sudamericana. Nuevas perspectivas, B. Meggers (editora). pp. 65-75. Washington, Taraxacum, NOVELLINO, P. 2002. Bioarqueología del Sur de Mendoza. En: Entre montañas y desiertos: Arqueología del sur de Mendoza, A. Gil y G. Neme (editores). pp. 119-139. Sociedad Argentina de Antropología. Buenos Aires.

OLIVA, F., J. MOIRANO y M. SAGHESSI. 1991. Estado de las investigaciones en el sitio Laguna de Puan 1. Boletín del Centro 2.

OUTES, F. 1907. Arqueología de San Blas (provincia de Buenos Aires). Anales del Museo Nacional de Buenos Aires 16:249-273.

PERES-NETO, P.R., y D.A. JACKSON. 2001. How well do multivariate data sets match? The advantages of a Procrustean superimposition approach over the Mantel test. Oecologia 129:169-178.

PEREZ, S.I. 2006. El poblamiento holocenico del Sudeste de la Región Pampeana: un estudio de morfometría geométrica craneofacial. Tesis doctoral inédita. Universidad Nacional de La Plata, La Plata.

PEREZ, SI. 2007. Artificial cranial deformation in South America: a geometric morphometrics approximation. Journal of Archaeological Science 34: 1649-1658.
PEREZ, S.I., V. BERNAL, y P.N. GONZALEZ. 2006. Differences between sliding semi-landmark methods in geometric morphometrics, with an application to human craniofacial and dental variation. Journal of Anatomy 208:769-784.

PODESTÁ, C. e I. PEREDA. 1979. Excavación del cementerio Las Lajitas (Neuquén). Relaciones de la Sociedad Argentina de Antropología, Nueva Serie, XIII: 117-132.

R DEVELOPMENT CORE TEAM. 2008. R: a language and environment for statistical computing. R Foundation for Statistical Computing, Vienna, Austria. http:// www.R-project.org

ROHLF, F.J. 1993. Relative warps analysis and an example of its application to Mosquito wings. En: Contributions to Morphometrics, L.F. Marcus, E. Bello y A. GarcíaValdecasas (editors). Monografías del Museo Nacional de Ciencias Naturales, pp. 132-159. Madrid.

ROHLF, F.J. 1996. Mophometric spaces, shape components and the effects of linear transformations. En: Advances in Morphometrics, L.F. Marcus, M. Corti, A. Loy, D. Slice y G. Naylor (editors), pp. 117-129. Plenum Press, New York.

ROHLF, F.J. 1999. Shape statistics: Procrustes superimpositions and tangent spaces. Journal of Classification 16: 197-223.

ROHLF, F.J. 2008. tps serie softwares. Disponible en http// life.bio.sunysb.edu/morph/.

ROHLF, F.J y D.E. SLICE. 1990. Extensions of the Procrustes Method for the optimal superimposition of landmarks. Systematic Zoology 39:40-59.

SANGUINETTI DE BÓRMIDA, A.C. 1981. Síntesis del desarrollo cultural de la cuenca interior del río Limay en el área de El Chocón y su ubicación en el cuadro de la prehistoria de Patagonia. Trabajos de Prehistoria 1:169-177

SHEETS, H.D. 2003. IMP-Integrated Morphometrics Package. Department of Physics, Canisius College, New York, Buffalo.

SLICE, D.E. 2001. Landmark coordinates aligned by Procrustes analysis do not lie in Kendall's shape space. Systematic Biology 50:141-149.

TORRES-ROUFF, C. 2002. Cranial vault modification and ethnicity in middle horizon San Pedro de Atacama, Chile. Current Anthropology 43-1:163-171.

TORRES-ROUFF, C. 2003. Shaping Identity: Cranial Vault Modification in the Pre-Columbian Andes, Doctoral Thesis work, University of California.

VAYA, C.A. 1981. "Consideraciones sobre el esqueleto hallado en el Alero del Dique - El Chocón - Provincia de Neuquén" en: "Prehistoria de la Cuenca del Río Limay Primera parte: Los Aleros del Limay Norte (Area de El 
Chocón)" pag. 135 - 151. Ed. Imprenta de la Facultad de Filosofía y Letras de la Universidad de Buenos Aires, Instituto de Ciencias Antropológicas.
VIGNATI, M. A. 1931. Investigaciones antropológicas en el litoral marítimo subatlántico bonaerense. Notas Preliminares del Museo de La Plata 1:19-31. 